\title{
Noncontraceptive benefits of the estradiol valerate/dienogest combined oral contraceptive: a review of the literature
}

This article was published in the following Dove Press journal:

International Journal of Women's Health

2 August 2014

Number of times this article has been viewed

Rossella E Nappi ${ }^{1}$

Marco Serrani ${ }^{2}$

Jeffrey $T$ Jensen ${ }^{3}$

'Department of Obstetrics and Gynecology, Research Centre for Reproductive Medicine, IRCCS Policlinico San Matteo Foundation, University of Pavia, Pavia, Italy; ${ }^{2}$ Global Medical Affairs Women's Healthcare, Bayer HealthCare Pharmaceuticals, Berlin, Germany; ${ }^{3}$ Department of Obstetrics and Gynecology, Oregon Health and Science University, Portland, OR, USA
Correspondence: Rossella E Nappi Research Center for Reproductive Medicine, Obstetrics and Gynecology Unit, IRCCS Policlinico San Matteo Foundation, Piazzale Golgi 2, 27I 00 Pavia, Italy

$\mathrm{Tel}+39038250$ I56I

Fax +390382 423233

Email renappi@tin.it

\begin{abstract}
Combined oral contraceptives formulated to include estradiol $\left(\mathrm{E}_{2}\right)$ have recently become available for the indication of pregnancy prevention. A combined estradiol valerate and dienogest pill ( $\left.\mathrm{E}_{2} \mathrm{~V} / \mathrm{DNG}\right)$, designed to be administered using an estrogen step-down and a progestin step-up regimen over 26 days of active treatment followed by 2 days of placebo (26/2-day regimen), has also undergone research to assess the potential for additional noncontraceptive benefits. Randomized, placebo-controlled studies have demonstrated that $\mathrm{E}_{2} \mathrm{~V} /$ DNG is an effective treatment for heavy menstrual bleeding - a reduction in median menstrual blood loss approaching $90 \%$ occurs after 6 months of treatment. To date, $\mathrm{E}_{2} \mathrm{~V} / \mathrm{DNG}$ is the only oral contraceptive approved for this indication. Comparator studies have also demonstrated a reduction in hormone withdrawal-associated symptoms in users of $\mathrm{E}_{2} \mathrm{~V} / \mathrm{DNG}$ compared with a conventional 21/7-day regimen of ethinylestradiol/levonorgestrel. Other potential noncontraceptive benefits associated with $\mathrm{E}_{2} \mathrm{~V} / \mathrm{DNG}$, like improvement in dysmenorrhea, sexual function, and quality of life, are comparable with those associated with other combined oral contraceptives and are discussed further in this review.
\end{abstract}

Keywords: heavy menstrual bleeding, hormone withdrawal-associated symptoms, quality of life

\section{Introduction}

Over the last 50 years, combined oral contraceptives (COCs) have become a widely accepted form of birth control. They have also undergone considerable evolution in the dose and type of estrogen, the type of progestins, and the variety of regimens used, as well as the inclusion of other pharmaceuticals that could be beneficial to menstruating women (eg, folic acid and iron). These developments have been driven, in part, to improve tolerability, meet women's requirements, and provide additional benefits. Although the described noncontraceptive health benefits of COCs are numerous, ${ }^{1}$ only a few noncontraceptive indications have been specifically approved by regulatory authorities for some formulations; these include: the treatment of acne and/or hirsutism as well as other signs of androgenization in women, such as androgenetic alopecia, with ethinyl estradiol (EE)/drospirenone (YAZ ${ }^{\circledR}$; Bayer HealthCare Pharmaceuticals, Berlin, Germany), EE/ cyproterone acetate (Dianette/Diane-35; Bayer Schering Pharma AG, Berlin, Germany), EE/norgestimate (Ortho Tri-Cyclen ${ }^{\circledR}$; Janssen Pharmaceuticals Inc., Titusville, NJ, USA), and $\mathrm{EE} /$ norethindrone acetate with ferrous fumarate (Estrostep $\mathrm{Fe}^{\circledR}$; Warner Chilcott Company, LLC, Rockaway, NJ, USA), ${ }^{2-6}$ treatment of premenstrual dysphoric disorder $(\mathrm{PMDD})$ with EE/drospirenone $\left(\mathrm{YAZ}^{\circledR}\right){ }^{2}$ and the treatment of heavy menstrual bleeding $(\mathrm{HMB})$ with estradiol valerate $\left(\mathrm{E}_{2} \mathrm{~V}\right) /$ dienogest $(\mathrm{DNG})$ (Qlaira ${ }^{\circledR} / \mathrm{Natazia}^{\circledR}$; Bayer HealthCare Pharmaceuticals). ${ }^{7}$ Epidemiologic studies have also demonstrated that COCs 
reduce the risk of endometrial, ovarian, and colon cancers ${ }^{8,9}$ and all cause mortality. ${ }^{10}$

Previous attempts to improve the tolerability of COCs, by replacing $E E$ with 17-beta-estradiol $\left(\mathrm{E}_{2}\right)$, resulted in poor cycle control, particularly when $\mathrm{E}_{2}$ was administered as part of a monophasic or a biphasic regimen. ${ }^{11,12}$ A novel 26/2-day dynamic-dose regimen ( 26 days of hormone, followed by a 2-day hormone-free interval [HFI]) of $\mathrm{E}_{2} \mathrm{~V} / \mathrm{DNG}$ (Qlaira ${ }^{\circledR} /$ Natazia $\left.^{\circledR}\right)$, administered using an estrogen step-down and progestin step-up approach, has been developed to provide efficient ovulation inhibition, high contraceptive efficacy, and good cycle control, with an acceptable tolerability profile. ${ }^{11} \mathrm{E}_{2} \mathrm{~V} / \mathrm{DNG}$ has been approved for contraceptive use in Europe and North America, ${ }^{11,13,14}$ and more recently, approved for the treatment of HMB, based on the results of two multicenter trials conducted in Europe/Australia and North America. ${ }^{15,16}$

Since its introduction, $\mathrm{E}_{2} \mathrm{~V} / \mathrm{DNG}$ has been assessed in a number of studies designed to better define its noncontraceptive benefits. This paper reviews the noncontraceptive therapeutic benefits associated with the use of $\mathrm{E}_{2} \mathrm{~V} / \mathrm{DNG}$.

\section{Methods}

A PubMed literature search for original research articles published between January 1, 2000 and May 7, 2014, using the terms "estradiol valerate" and "dienogest", "Qlaira", and " $E_{2} V / D N G$ ", yielded 206 unique citations. From the initial electronic search, 16 original research articles reporting the $\mathrm{E}_{2} \mathrm{~V} / \mathrm{DNG}$ oral contraceptive were identified based on abstract/title information and retrieved; ${ }^{11,13,15-28}$ the full articles were assessed, and eight articles that reported noncontraceptive benefits of $\mathrm{E}_{2} \mathrm{~V} / \mathrm{DNG}$ (loosely defined as any perceived benefit beyond safety and contraceptive efficacy, or related surrogate outcomes) were identified for inclusion. ${ }^{13,15-18,22,24,28}$ Of the other publications, one was a pooled study summarizing menstrual blood loss (MBL) data across two individual studies previously identified, and was included as appropriate. ${ }^{23}$ The other seven articles reported on outcomes that were not the focus of this review but were included, where appropriate, as supportive references. ${ }^{11,19-21,25-27}$ Ten other pertinent articles were identified from published manuscripts known to the authors or from unpublished manuscripts that were available to them and were included for discussion, ${ }^{14,29-37}$ but three others were not included as the outcomes reported were not the focus of this review. ${ }^{38-40}$ Thus, 19 articles that reported some noncontraceptive benefits of $\mathrm{E}_{2} \mathrm{~V} / \mathrm{DNG}$ formed the main bulk of this narrative review.

\section{Noncontraceptive benefits of $E_{2} V / D N G$ Bleeding profile}

The drive to develop $\mathrm{E}_{2}$-based oral contraceptives has, in part, been due to an interest in reducing the serious adverse effects related to the hepatic and hemostatic changes associated with EE. However, early attempts at producing $\mathrm{E}_{2}$-based oral contraceptives have been limited by poor cycle stability, attributed to the rapid metabolism of $E_{2}$ to the weaker estrogen, estrone, which is unable to maintain stable endometrial proliferation. Moreover, the rate of $\mathrm{E}_{2}$ metabolism may be influenced by the progestin, and as such, those progestins with minimal impact on $\mathrm{E}_{2}$ metabolism and endometrial stroma stability would be expected to improve cycle stability. DNG is a 19-norprogestin derivative with high specificity for the progesterone receptor, antiandrogenic properties, and minimal impact on lipid and carbohydrate metabolism. It has no glucocorticoid, antimineralocorticoid, or antiestrogenic activity. ${ }^{41}$ In addition, DNG has potent antiproliferative effects on the endometrium, as well as anti-inflammatory and antiangiogenic properties. ${ }^{42}$

The $\mathrm{E}_{2} \mathrm{~V} / \mathrm{DNG} 26 / 2$ cycle consists of $\mathrm{E}_{2} \mathrm{~V} 3 \mathrm{mg}$ on days 1-2, $\mathrm{E}_{2} \mathrm{~V} 2 \mathrm{mg} / \mathrm{DNG} 2 \mathrm{mg}$ on days 3-7, $\mathrm{E}_{2} \mathrm{~V} 2 \mathrm{mg} / \mathrm{DNG}$ $3 \mathrm{mg}$ on days $8-24, \mathrm{E}_{2} \mathrm{~V} 1 \mathrm{mg}$ on days $25-26$, and placebo on days $27-28 .{ }^{11}$ This regimen has been shown to effectively inhibit ovulation and provide extraovarian contraceptive effects (such as reducing endometrial thickness and cervical mucus production). ${ }^{11,20}$ The phased delivery of hormones was designed to provide estrogen dominance at the start of the cycle and progestin dominance during the mid and later part of the cycle. The early estrogenic dominance allows for initial endometrial proliferation, thereby enhancing sensitivity to progestin action at midcycle and endometrial stroma stability. ${ }^{28}$ Endometrial stroma stability ensures a predictable bleeding profile with $\mathrm{E}_{2} \mathrm{~V} / \mathrm{DNG}$. Administration of $\mathrm{E}_{2}$ only at the end of the cycle, along with a short (2 day) HFI, results in $\mathrm{E}_{2}$ levels that remain relatively stable throughout the cycle. ${ }^{27}$

$\mathrm{E}_{2} \mathrm{~V} / \mathrm{DNG}$ is an established contraceptive with a reducedbleed profile. ${ }^{16,28,35}$ In a seven-cycle, multicenter, doubleblind, double-dummy, randomized, controlled trial (RCT) in healthy women aged $18-50$ years, $\mathrm{E}_{2} \mathrm{~V} / \mathrm{DNG}$ was shown to achieve shorter and lighter bleeding and resulted in a higher proportion of women without withdrawal bleeding compared with the monophasic combination of EE $20 \mu \mathrm{g} /$ levonorgestrel (LNG) $100 \mu \mathrm{g}$ administered in a 21/7-day regimen ( 21 days of hormone, followed by a 7 -day HFI) (the proportion who experienced withdrawal bleeding per cycle through cycles $1-7$ was $77.7 \%-83.2 \%$ with $\mathrm{E}_{2} \mathrm{~V} / \mathrm{DNG}$ 
and $89.5 \%-93.8 \%$ with EE/LNG $[P<0.0001$ per cycle $]) .{ }^{28}$ For some women, however, this might be considered a disadvantage as withdrawal bleeding may reassure them that they are not pregnant. Although these data suggested that $\mathrm{E}_{2} \mathrm{~V} / \mathrm{DNG}$ may reduce MBL to a greater extent than EE/ LNG, the study also showed that the incidence of intracyclic bleeding, adverse events, and satisfaction with therapy associated with the two COCs were similar. ${ }^{28}$

\section{Dysmenorrhea}

COCs are widely used for the management of primary dysmenorrhea as the condition has long been shown to respond favorably to ovulation inhibition. ${ }^{43}$ In addition, COCs suppress endometrial growth, thereby reducing the proliferation of endometrial tissue. In an RCT comparing $\mathrm{E}_{2} \mathrm{~V} / \mathrm{DNG}$ and $\mathrm{EE} / \mathrm{LNG}$ in 507 women with primary dysmenorrhea over three cycles of treatment, both COCs alleviated dysmenorrhea and decreased the number of days with dysmenorrheic pain, compared with baseline, to a similar amount ( $-4.6 \pm 4.6$ days and $-4.2 \pm 4.2$ days for the $\mathrm{E}_{2} \mathrm{~V} /$ DNG and EE/LNG groups, respectively) $(P=0.34) .{ }^{29}$

\section{Heavy menstrual bleeding}

$\mathrm{E}_{2} \mathrm{~V} / \mathrm{DNG}$ is currently the only COC indicated for the treatment of HMB (defined as blood loss of at least $80 \mathrm{~mL}$ per menstrual cycle $\left.{ }^{44}\right)$. Approval was based on two rigorous, identically designed, double-blind, placebo-controlled $\mathrm{RCTs}^{15,16}$ in women with heavy and/or prolonged menstrual bleeding without organic pathology (ie, HMB due to endometrial dysfunction, using International Federation of Gynecology and Obstetrics [FIGO] terminology ${ }^{45}$ ). Menstrual bleeding was recorded daily in electronic diaries throughout the study, and MBL was estimated from sanitary protection used by the women, using a modified version of the alkaline hematin method. ${ }^{46}$ The primary efficacy end point across both studies (as requested by the USA Food and Drug Administration) was based on a previously unused composite of eight stringent criteria for "complete response" (ie, a return to "menstrual normality") during a 90-day efficacy period, defined as the complete resolution of qualifying abnormal menstrual symptoms, including a reduction in MBL to below $80 \mathrm{~mL}$ and $\geq 50 \%$ reduction in MBL, in women with HMB (Table 1).

In the first of these RCTs carried out in Europe and Australia, ${ }^{15} 231$ otherwise healthy women with confirmed heavy, prolonged or frequent menstrual bleeding were randomized (2:1) to seven cycles of $\mathrm{E}_{2} \mathrm{~V} / \mathrm{DNG}$ or placebo. The proportion of women with a return to "menstrual normality" was significantly higher with $\mathrm{E}_{2} \mathrm{~V} / \mathrm{DNG}$ versus placebo $(29.5 \%$ vs $1.2 \%)(P<0.0001)$. In the second RCT, carried out in 128 women in the United States and Canada, ${ }^{16}$ the findings were similar $\left(29.2 \% \mathrm{E}_{2} \mathrm{~V} / \mathrm{DNG}\right.$ vs $2.9 \%$ placebo $)$ $(P<0.001)$.

In a pooled analysis of data from these two RCTs, median MBL across both studies was found to have decreased by $88 \%$ with $\mathrm{E}_{2} \mathrm{~V} / \mathrm{DNG}$ compared with $24 \%$ with placebo, after 6 months of treatment. The onset of action of $E_{2} V / D N G$ was shown to be rapid, with the largest reductions in MBL achieved as early as the first withdrawal bleed after $\mathrm{E}_{2} \mathrm{~V} / \mathrm{DNG}$ initiation and maintained with no loss of effect (and even some further gradual improvement) with continued treatment. ${ }^{36}$

The data from the two RCTs were reanalyzed in another pooled analysis, using the definition of treatment

Table I Primary efficacy outcomes* used in two identically designed, double-blind, placebo-controlled, randomized controlled studies with estradiol valerate/dienogest, in women with heavy and/or prolonged menstrual bleeding without organic pathology

\begin{tabular}{ll}
\hline Efficacy condition & Definition (per $\mathbf{9 0}$-day period) \\
\hline $\mathrm{I}$ & No bleeding episodes lasting $>7$ days \\
2 & No more than four bleeding episodes \\
3 & No bleeding episodes with a blood loss volume of $\geq 80 \mathrm{~mL}$ \\
4 & No more than one bleeding episode increase from baseline \\
5 & Total number of bleeding days $\leq 24$ \\
6 & No increase from baseline in total number of bleeding days \\
7 & Decrease of $\geq 2$ days between maximum duration during run-in phase and efficacy phase (if enrolled \\
& with prolonged bleeding) \\
& $\begin{array}{l}\text { Blood loss volume associated with each episode }<80 \mathrm{~mL} \text { and decreased by } 50 \% \text { or more from the } \\
\text { average of the qualifying bleeding episodes (where the qualifying bleeding episodes are those with } \\
\text { a blood loss volume } \geq 80 \text { mL per episode) that occurred during the run-in phase (if enrolled with } \\
\text { excessive bleeding) }\end{array}$ \\
\hline
\end{tabular}

Notes: *Fraser et al ${ }^{15}$ and Jensen et $\mathrm{l}^{16}$ had to use these outcomes as mandated by the US Food and Drug Administration. ${ }^{62}$ The primary efficacy outcome was the proportion of women who had a complete response (ie, restoration of "normal menstruation") during a 90-day efficacy interval versus the 90 -day run-in interval. A complete response was defined as a composite of up to eight individual criteria defined in the table. 
success that was previously employed in another RCT comparing the efficacy and safety of the levonorgestrelreleasing intrauterine system with that of oral medroxyprogesterone acetate in women with HMB. ${ }^{47}$ Using these criteria, the proportions of patients successfully treated (ie, reduction in $\mathrm{MBL}$ to $<80 \mathrm{~mL}$ and a $\geq 50 \%$ reduction compared with baseline) with seven cycles of $\mathrm{E}_{2} \mathrm{~V} /$ DNG and placebo, respectively, were $63.6 \%$ and $11.9 \%$ $(P<0.001){ }^{23}$

There are currently no head-to-head trials comparing $\mathrm{E}_{2} \mathrm{~V} /$ DNG with other COCs or other medical treatment options in the management of HMB, and as such, only indirect comparisons can be made. Commonly used medical therapies for HMB include the levonorgestrel-releasing intrauterine system, tranexamic acid, EE-based COCs, oral progestins, and nonsteroidal anti-inflammatory drugs (NSAIDs). Figure 1 allows an indirect comparison of the reduction in MBL achieved with $\mathrm{E}_{2} \mathrm{~V} / \mathrm{DNG}$ relative to the other various medical therapies, in women with HMB without organic pathology. The reduction from baseline in MBL achieved with $\mathrm{E}_{2} \mathrm{~V} / \mathrm{DNG}$ (median 88\% reduction after 6 months) ${ }^{36}$ appears to approach that achieved with the levonorgestrelreleasing intrauterine system (median 91\%-95\% after 6 months) and appears superior to other oral treatments. ${ }^{47-50}$ However, the main limitations of such interstudy comparison include patient heterogeneity and deviations in the alkaline hematin method, which requires consistent use of validated sanitary materials, and as such, may mask variations in efficacy between studies.

\section{Quality of life (QoL) implications of HMB treatment}

While QoL was not directly assessed in the two RCTs assessing $\mathrm{E}_{2} \mathrm{~V} / \mathrm{DNG}$ in the treatment of $\mathrm{HMB}$, the effect of treatment on HMB-related impairment of work productivity and activities of daily living has been assessed. ${ }^{18,32}$ These assessments showed that the benefits of $\mathrm{E}_{2} \mathrm{~V} / \mathrm{DNG}$ in reducing MBL could be translated into a consistent positive impact on work productivity and activities of daily living. Moreover, these improvements resulted in savings of US\$22-62 and US\$18-56 per month, associated with better work productivity and improvements in activities of daily living, respectively, in the study conducted in Europe and Australia. ${ }^{32}$ In the US and Canadian study, improvements in work productivity and activities of daily living with $\mathrm{E}_{2} \mathrm{~V} / \mathrm{DNG}$ resulted in monthly saving of US\$80.2 and Can\$70.8, and US\$84.9 and Can\$73.5, respectively, in the two countries. ${ }^{18}$

\section{Hormone-associated withdrawal symptoms}

Some users of conventional COCs with cyclical 21/7-day regimens experienced bothersome symptoms during the HFI. ${ }^{51}$ These are generally believed to be the result of estrogen withdrawal/fluctuation during the HFI and can include

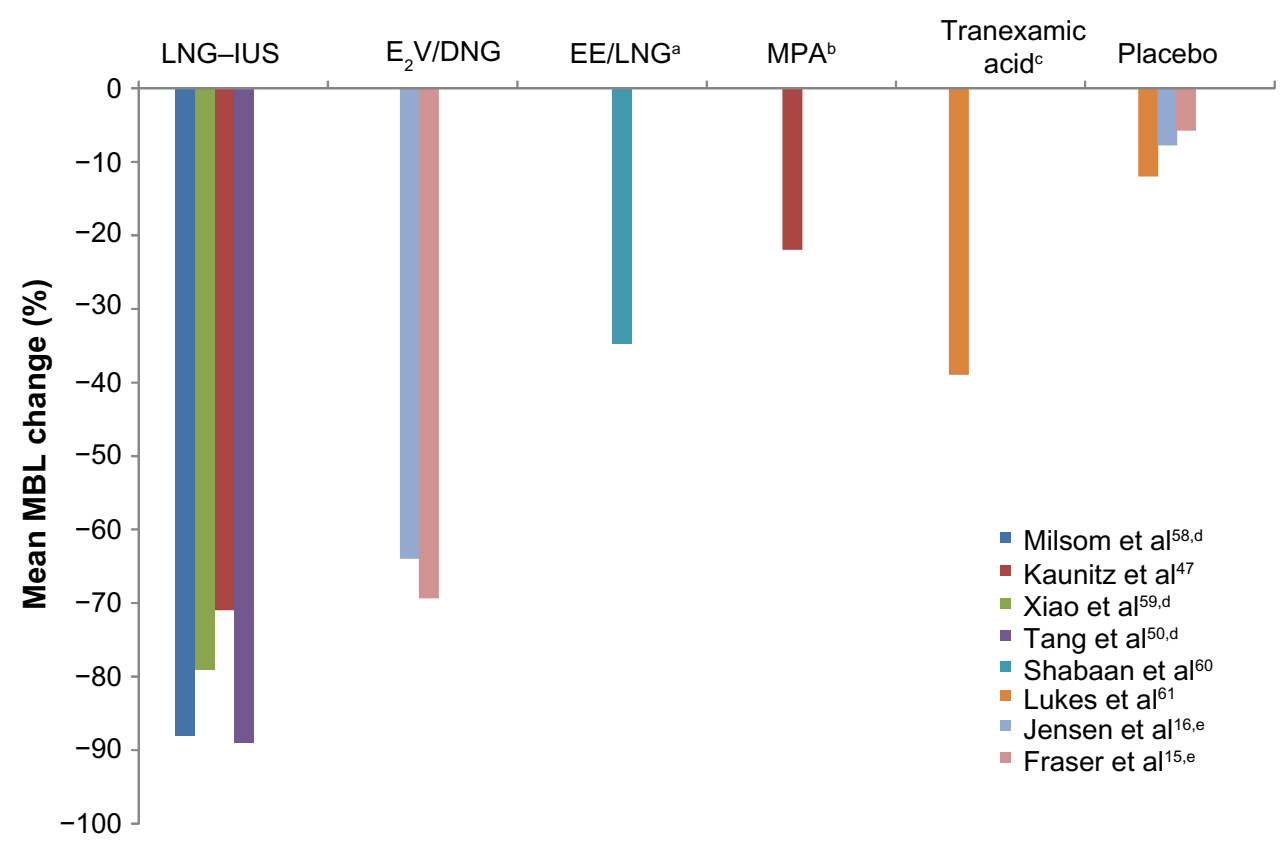

Figure I Bleeding reduction after 6 months of treatment with selected medical therapies, measured using the alkaline hematin method (data from randomized control trial unless otherwise stated). ${ }^{15,16,47,50,58-61}$

Notes: ${ }^{b} 10 \mathrm{mg}$ daily from day 16 to 25 of cycle; ${ }^{\mathrm{E} E E} 30 \mu \mathrm{g} / \mathrm{LNG} 150 \mu \mathrm{g}$ in a $2 \mathrm{I} / 7$ regimen after 12 months; ${ }^{\mathrm{C}} .3 \mathrm{~g}$ TID on days I to 5 of cycle; ${ }^{\mathrm{d}}$ nonrandomized trial; ${ }^{\mathrm{eMBL}}$ reduction between 90 -day run-in phase and 90 -day efficacy phase.

Abbreviations: DNG, dienogest; $\mathrm{E}_{2} \mathrm{~V}$, estradiol valerate; $\mathrm{EE}$, ethinyl estradiol; LNG-IUS, levonorgestrel-releasing intrauterine system; LNG, levonorgestrel; MBL, menstrual blood loss; MPA, medroxyprogesterone acetate; TID, three times daily. 
headaches and pelvic pain, nausea or vomiting, bloating, and breast tenderness. ${ }^{51,52}$ Consequently, it is hypothesized that eliminating or reducing the HFI should reduce the frequency and/or severity of these hormone withdrawal-associated symptoms. ${ }^{53}$

The effect of the 26/2-day dynamic-dosing $\mathrm{E}_{2} \mathrm{~V} / \mathrm{DNG}$ regimen in reducing the severity of hormone withdrawalassociated symptoms in women prone to these symptoms was evaluated in two Phase III RCTs using 21/7-day regimen COC comparators. ${ }^{17,31}$ The Phase III, multicenter, double-blind HARMONY I and II RCTs showed that $\mathrm{E}_{2} \mathrm{~V} / \mathrm{DNG}$ provided significantly greater reductions in the frequency and intensity of headache and pelvic pain during the HFI than did 21/7-day regimens with triphasic EE/norgestimate or $\mathrm{EE} / \mathrm{LNG}$, in otherwise healthy women aged $18-50$ years (Figure 2). ${ }^{17,31}$ The use of rescue medication was also significantly reduced with $\mathrm{E}_{2} \mathrm{~V} / \mathrm{DNG}$ compared with the triphasic EE/norgestimate or EE/LNG COCs. These studies suggest that $\mathrm{E}_{2} \mathrm{~V} / \mathrm{DNG}$ may be a good option for women who experience hormone withdrawal-associated symptoms with traditional 21/7-day regimen COCs. The 26/2-day dynamic dosing regimen of $\mathrm{E}_{2} \mathrm{~V} / \mathrm{DNG}$, with its shortened HFI, has been shown to provide stable levels of $\mathrm{E}_{2}$ throughout the 28-day cycle, including during the HFI, which may, in part, explain its benefit with respect to these symptoms. ${ }^{27}$

Other COCs taken in regimens that eliminate (ie, continuous use) or reduce the HFI (eg, 24/4-day regimens) have reported improvements in hormone withdrawal-associated symptoms. ${ }^{53}$ There are currently no head-to-head data comparing the effect of $\mathrm{E}_{2} \mathrm{~V} / \mathrm{DNG}$ with these regimens.

\section{Menstrual-related migraine}

$\mathrm{E}_{2} \mathrm{~V} / \mathrm{DNG}$ has been shown to have a positive effect in women with menstrual-related migraine. A prospective pilot study in 32 women with menstrual-related migraine showed that six cycles of $\mathrm{E}_{2} \mathrm{~V} / \mathrm{DNG}$ significantly reduced the number of migraine attacks and the amount of analgesic used versus baseline. ${ }^{33}$ In addition, in those with concomitant dysmenorrhea at baseline, complete remission of menstrual cramps was reported by $59 \%(17 / 29)$ and $61 \%$ (17/28) of these women at cycles 3 and 6, respectively. Persistence of dysmenorrhea was shown to be a potential feature associated with refractory head pain in a subgroup of women with dysmenorrhea. However, the open label, noncomparator nature of this study makes it impossible to draw robust conclusions as the study provides no reference for the observed changes. ${ }^{33}$

It must be kept in mind that a cautious approach regarding any COC use is recommended for women with a history of headache. A clear diagnostic distinction between common headache and migraine, either with or without aura is needed, especially as both the American College of Obstetricians and Gynecologists and the World Health Organization list migraine with aura as an absolute contraindication to the use of COCs, due to the increased risk of stroke. ${ }^{54,55}$ In the absence of aura, other individual risk factors should be taken into account. Women who develop new onset migraine or a worsening of migraine symptoms while using COCs should discontinue use. ${ }^{56}$

\section{Sexual function and QoL}

Oral contraceptives are not thought to improve sexual function, aside from the reduction in concern for risk of pregnancy. However, oral contraceptives containing progestins with antiandrogenic activity, such as DNG, may theoretically be associated with decreased libido, ${ }^{57}$ and it is common for women with associated sexual dysfunction to be switched to oral contraceptives containing progestins with androgenic activity, such as LNG. ${ }^{34}$ A preliminary study in 57 sexually active, healthy women showed that $\mathrm{E}_{2} \mathrm{~V} / \mathrm{DNG}$ improved QoL and had a positive effect on sexuality over six cycles of use, ${ }^{24}$ however, this study was open label, and without
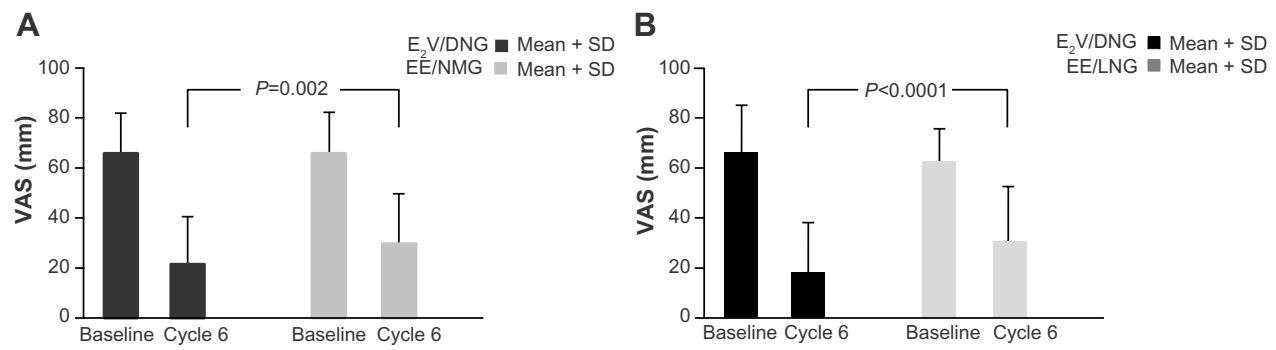

Figure 2 Change from baseline to cycle 6 in the average of the three highest VAS values on cycle days 22-28, for the hormone withdrawal-associated symptoms of headache or pelvic pain, in women who received treatment with $E_{2} V / D N G$ compared with (A) triphasic EE/NGM and (B) EE/LNG.

Notes: (A) Reproduced from Jensen JT, Parke S, Mellinger U, et al, Eur J Contracept Reprod Health Care, 2013;18(4):274-283, Copyright @ 2013, Informa Healthcare. Reproduced with permission of Informa Healthcare. ${ }^{17}$ (B) Reproduced from Macias G, Merki-Feld GS, Parke S, et al, J Obstet Gynaecol, 20I3;33(6):59I-596, Copyright () 20I3, Informa Healthcare. Reproduced with permission of Informa Healthcare. ${ }^{31}$

Abbreviations: DNG, dienogest; $E_{2} V$, estradiol valerate; EE, ethinyl estradiol; LNG, levonorgestrel; NGM, norgestimate; SD, standard deviation; VAS, visual analog scale. 


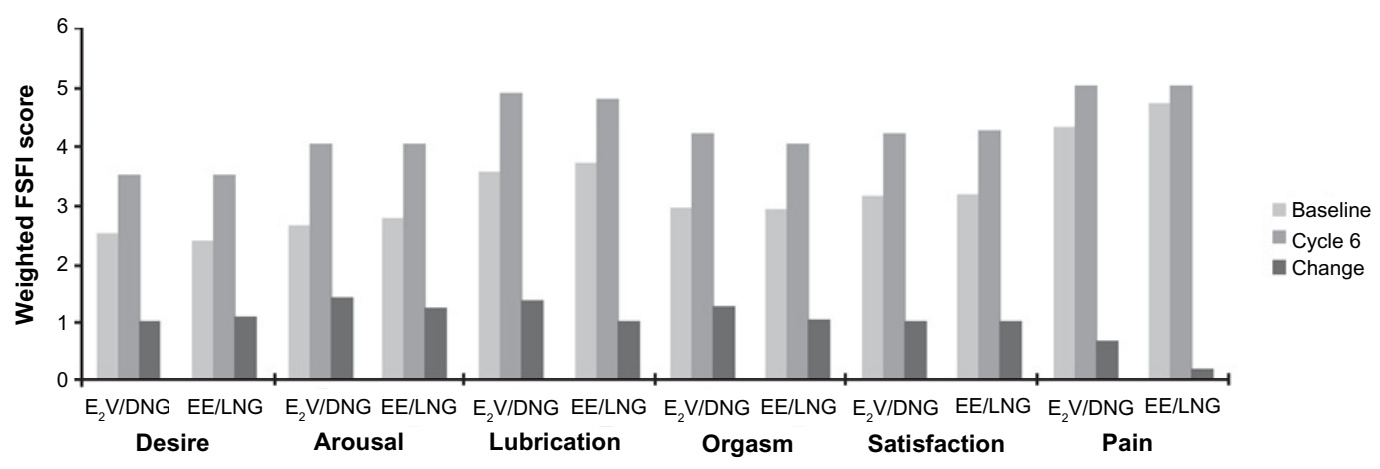

Figure 3 Scores of the Female Sexual Function Index subdomains, for $E_{2}$ V/DNG and EE/LNG, at baseline and cycle 6, and the change from baseline.

Note: Reproduced from Change to either a nonandrogenic or androgenic progestin-containing oral contraceptive preparation is associated with improved sexual function in women with oral contraceptive-associated sexual dysfunction. Davis SR, Bitzer J, Giraldi A, et al. J Sex Med. 20I3;I0(I2):3069-3079. Copyright @ 2013 International Society for Sexual Medicine. ${ }^{34}$

Abbreviations: DNG, dienogest; $\mathrm{E}_{2} \mathrm{~V}$, estradiol valerate; EE, ethinyl estradiol; FSFI, Female Sexual Function Index, LNG, levonorgestrel.

a comparator. More recently, a multicenter, double-blind, noninferiority RCT compared the effects of six cycles of $\mathrm{E}_{2} \mathrm{~V} /$ DNG with EE/LNG on sexual function, in 276 women with COC-associated sexual dysfunction. ${ }^{34}$ Similar improvements in all domains of the Female Sexual Function Index (FSFI) were demonstrated with $\mathrm{E}_{2} \mathrm{~V} / \mathrm{DNG}$ and $\mathrm{EE} / \mathrm{LNG}$ recipients, with no significant between-group differences (Figure 3). The mean increase (improvement) in the sum of the FSFI Desire and Arousal component scores from baseline to cycle 6 were $5.90 \pm 5.45$ for $\mathrm{E}_{2} \mathrm{~V} / \mathrm{DNG}$ and $5.79 \pm 6.17$ for $\mathrm{EE} / \mathrm{LNG}$ (both $P<0.0001$ ), and all other efficacy parameters were also equally improved with the two COCs. Overall, these results suggest that $\mathrm{E}_{2} \mathrm{~V} / \mathrm{DNG}$ does not have a detrimental effect on sexual function.

\section{Other benefits}

There is evidence to suggest that $\mathrm{E}_{2} \mathrm{~V} / \mathrm{DNG}$ may have a positive influence on acne and hyperandrogenism. ${ }^{30}$ In a small 1-year preliminary observational study in 36 young women with polycystic ovary syndrome (PCOS) and mild or moderate acne, 12 cycles of $\mathrm{E}_{2} \mathrm{~V} / \mathrm{DNG}$ provided a significant improvement of acne in $53 \%$ of patients $(P<0.01)$ and a significant increase in sex hormone-binding globulin levels at 6 and 12 months $(P<0.001) .{ }^{30}$ However, larger, longer-term RCTs that include a comparator are needed to confirm whether $\mathrm{E}_{2} \mathrm{~V} / \mathrm{DNG}$ offers any advantage over other COC formulations, for the treatment of acne. $\mathrm{E}_{2} \mathrm{~V} /$ DNG has also been assessed as a strategy for endometrial preparation prior to operative hysteroscopy, with two small randomized studies supporting that pretreatment with $\mathrm{E}_{2} \mathrm{~V} /$ DNG improved the subjective ease of the procedure. ${ }^{22,37}$ Again, larger RCTs are needed to confirm whether $\mathrm{E}_{2} \mathrm{~V} /$ DNG pretreatment offers any advantage over other COC formulations with regard to operative hysteroscopy procedures.

\section{Conclusion}

$\mathrm{E}_{2} \mathrm{~V} / \mathrm{DNG}$ is an established contraceptive with a reduced-bleed profile and is currently the only COC approved for treatment of HMB. It may be a good alternative for women susceptible to hormone withdrawal-associated symptoms with COCs taken in the conventional 21/7-day regimen. Whether the reduction in hormone withdrawal-associated symptoms is due to the components of the formulation, the dosing regimen, or both, remains to be fully established. The available evidence does not suggest that $\mathrm{E}_{2} \mathrm{~V} / \mathrm{DNG}$ has a detrimental impact on sexual function compared with LNG combination pills.

\section{Acknowledgments}

Medical writing support during development of this manuscript was provided by Mary Hines and Richard Glover of inScience Communications, Springer Healthcare. This assistance was funded by Bayer HealthCare Pharmaceuticals.

\section{Disclosure}

During the past 2 years, Dr Nappi had financial relationship (lecturer, member of advisory boards, and/or consultant) with Bayer HealthCare Pharmaceuticals, Ely Lilly, Gedeon-Richter, HRA Pharma, Merck Sharpe and Dohme, Novo Nordisk, Pfizer Inc., Shionogi Limited, and TEVA/Theramex. Dr Serrani is an employee of Bayer HealthCare Pharmaceuticals. Dr Jensen has received payments for consulting, from Agile Pharmaceuticals, Abbvie Pharmaceuticals, Bayer HealthCare Pharmaceuticals, ContraMed, Evofem Inc., HRA Pharma, Merck Pharmaceuticals, Teva Pharmaceuticals, and the Population Council; and for lectures, from Bayer and Merck; he has also received research 
funding from Abbvie, Bayer HealthCare Pharmaceuticals, the Population Council, the National Institutes of Health, and the Bill and Melinda Gates Foundation. These companies and organizations may have a commercial or financial interest in the results of this research and technology. The authors report no other conflicts of interest.

\section{References}

1. Schindler AE. Non-contraceptive benefits of oral hormonal contraceptives. Int J Endocrinol Metab. 2013;11(1):41-47.

2. $Y_{A Z}{ }^{\circledR}$ (drospirenone/ethinyl estradiol) tablets for oral use [prescribing information]. Monteville, NJ: Bayer HealthCare Pharmaceuticals, Inc.; 2012.

3. Dianette ${ }^{\circledR}$ [summary of product characteristics]. Berlin: Bayer Pharma AG; 2013.

4. Ortho Tri-Cyclen ${ }^{\circledR}$ tablets (norgestimate/ethinyl estradiol) tablets [prescribing information]. Titusville, NJ: Janssen Pharmaceuticals, Inc.; 2013.

5. ESTROSTEP ${ }^{\circledR} \mathrm{Fe}$ (norethindrone acetate and ethinyl estradiol tablets, USP and ferrous fumarate tablets) tablets [prescribing information] Rockaway, NJ: Warner Chilcott Company LLC; 2009.

6. Bayer Schering Pharma AG. Diane-35. Berlin-Wedding: Bayer Schering Pharma AG; 2010. Available from: http://www.pharmaline.co.il/images/ newsletterregistration/bayer/11022011/dianedr.pdf. Accessed March 20, 2014.

7. NATAZIA ${ }^{\circledR}$ (estradiol valerate and estradiol valerate/dienogest) tablets, for oral use [prescribing information]. Monteville, NJ: Bayer Health Care Pharmaceuticals, Inc.; 2013.

8. Veljković M, Veljković S. [The risk of breast cervical, endometrial and ovarian cancer in oral contraceptive users]. Med Pregl. 2010;63(9-10): 657-661. Serbian.

9. Dossus L, Allen N, Kaaks R, et al. Reproductive risk factors and endometrial cancer: the European Prospective Investigation into Cancer and Nutrition. Int J Cancer. 2010;127(2):442-451.

10. Vessey M, Yeates D, Flynn S. Factors affecting mortality in a large cohort study with special reference to oral contraceptive use. Contraception. 2010;82(3):221-229.

11. Endrikat J, Parke S, Trummer D, Schmidt W, Duijkers I, Klipping C. Ovulation inhibition with four variations of a four-phasic estradiol valerate/dienogest combined oral contraceptive: results of two prospective, randomized, open-label studies. Contraception. 2008;78(3):218-225.

12. Ågren UM, Anttila M, Mäenpää-Liukko K, et al. Effects of a monophasic combined oral contraceptive containing nomegestrol acetate and $17 \beta$-oestradiol in comparison to one containing levonorgestrel and ethinylestradiol on markers of endocrine function. Eur J Contracept Reprod Health Care. 2011;16(6):458-467.

13. Palacios S, Wildt L, Parke S, Machlitt A, Römer T, Bitzer J. Efficacy and safety of a novel oral contraceptive based on oestradiol (oestradiol valerate/dienogest): a Phase III trial. Eur J Obstet Gynecol Reprod Biol. 2010;149(1):57-62.

14. Nelson A, Parke S, Mellinger U, Zampaglione E, Schmidt A. Efficacy and safety of a combined oral contraceptive containing estradiol valerate/dienogest: results from a clinical study conducted in North America. J Womens Health (Larchmt). 2014;23(3):204-210.

15. Fraser IS, Römer T, Parke S, et al. Effective treatment of heavy and/ or prolonged menstrual bleeding with an oral contraceptive containing estradiol valerate and dienogest: a randomized, double-blind Phase III trial. Hum Reprod. 2011;26(10):2698-2708.

16. Jensen JT, Parke S, Mellinger U, Machlitt A, Fraser IS. Effective treatment of heavy menstrual bleeding with estradiol valerate and dienogest: a randomized controlled trial. Obstet Gynecol. 2011;117(4):777-787.

17. Jensen JT, Parke S, Mellinger U, Serrani M, Mabey RG. Hormone withdrawal-associated symptoms: comparison of oestradiol valerate/ dienogest versus ethinylestradiol/norgestimate. Eur J Contracept Reprod Health Care. 2013;18(4):274-283.
18. Wasiak R, Filonenko A, Vanness DJ, et al. Impact of estradiol valerate/ dienogest on work productivity and activities of daily living in women with heavy menstrual bleeding. $J$ Womens Health (Larchmt). 2013;22(4):378-384.

19. Raps M, Rosendaal F, Ballieux B, et al. Resistance to APC and SHBG levels during use of a four-phasic oral contraceptive containing dienogest and estradiol valerate: a randomized controlled trial. J Thromb Haemost. 2013;11(5):855-861.

20. Endrikat J, Parke S, Trummer D, Serrani M, Duijkers I, Klipping C. Pituitary, ovarian and additional contraceptive effects of an estradiolbased combined oral contraceptive: results of a randomized, open-label study. Contraception. 2013;87(2):227-234.

21. Blode H, Zeun S, Parke S, et al. Evaluation of the effects of rifampicin, ketoconazole and erythromycin on the steady-state pharmacokinetics of the components of a novel oral contraceptive containing estradiol valerate and dienogest in healthy postmenopausal women. Contraception. 2012;86(4):337-344.

22. Cicinelli E, Pinto V, Quattromini P, et al. Endometrial preparation with estradiol plus dienogest (Qlaira) for office hysteroscopic polypectomy: randomized pilot study. J Minim Invasive Gynecol. 2012;19(3):356-359.

23. Fraser IS, Jensen J, Schaefers M, Mellinger U, Parke S, Serrani M. Normalization of blood loss in women with heavy menstrual bleeding treated with an oral contraceptive containing estradiol valerate/ dienogest. Contraception. 2012;86(2):96-101.

24. Caruso S, Agnello C, Romano M, et al. Preliminary study on the effect of four-phasic estradiol valerate and dienogest (E2V/DNG) oral contraceptive on the quality of sexual life. J Sex Med. 2011;8(10): 2841-2850.

25. Junge W, Mellinger U, Parke S, Serrani M. Metabolic and haemostatic effects of estradiol valerate/dienogest, a novel oral contraceptive: a randomized, open-label, single-centre study. Clin Drug Investig. 2011;31(8):573-584.

26. Klipping C, Duijkers I, Parke S, Mellinger U, Serrani M, Junge W. Hemostatic effects of a novel estradiol-based oral contraceptive: an openlabel, randomized, crossover study of estradiol valerate/dienogest versus ethinylestradiol/levonorgestrel. Drugs R D. 2011;11(2): 159-170.

27. Zeun S, Lu M, Uddin A, Zeiler B, Morrison D, Blode H. Pharmacokinetics of an oral contraceptive containing oestradiol valerate and dienogest. Eur J Contracept Reprod Health Care. 2009;14(3):221-232.

28. Ahrendt HJ, Makalová D, Parke S, Mellinger U, Mansour D. Bleeding pattern and cycle control with an estradiol-based oral contraceptive: a seven-cycle, randomized comparative trial of estradiol valerate/dienogest and ethinyl estradiol/levonorgestrel. Contraception. 2009;80(5):436-444.

29. Petraglia F, Parke S, Serrani M, Mellinger U, Römer T. Estradiol valerate plus dienogest versus ethinylestradiol plus levonorgestrel for the treatment of primary dysmenorrhea. Int J Gynaecol Obstet. 2014;125(3):270-274.

30. Di Carlo C, Gargano V, Sparice S, Tommaselli GA, Bifulco G, Nappi C. Effects of an oral contraceptive containing estradiol valerate and dienogest on circulating androgen levels and acne in young patients with PCOS: an observational preliminary study. Gynecol Endocrinol. 2013;29(12):1048-1050.

31. Macias G, Merki-Feld GS, Parke S, Mellinger U, Serrani M. Effects of a combined oral contraceptive containing oestradiol valerate/dienogest on hormone withdrawal-associated symptoms: results from the multicentre, randomised, double-blind, active-controlled HARMONY II study. J Obstet Gynaecol. 2013;33(6):591-596.

32. Wasiak R, Filonenko A, Vanness DJ, et al. Impact of estradiol-valerate/ dienogest on work productivity and activities of daily living in European and Australian women with heavy menstrual bleeding. Int $J$ Womens Health. 2012;4:271-278.

33. Nappi RE, Terreno E, Sances G, et al. Effect of a contraceptive pill containing estradiol valerate and dienogest (E2V/DNG) in women with menstrually-related migraine (MRM). Contraception. 2013;88(3):369-375. 
34. Davis SR, Bitzer J, Giraldi A, et al. Change to either a nonandrogenic or androgenic progestin-containing oral contraceptive preparation is associated with improved sexual function in women with oral contraceptive-associated sexual dysfunction. J Sex Med. 2013;10(12): 3069-3079.

35. Nelson A, Parke S, Makalova D, Serrani M, Palacios S, Mellinger U. Efficacy and bleeding profile of a combined oral contraceptive containing oestradiol valerate/dienogest: a pooled analysis of three studies conducted in North America and Europe. Eur J Contracept Reprod Health Care. 2013;18(4):264-273.

36. Fraser IS, Parke S, Mellinger U, Machlitt A, Serrani M, Jensen J. Effective treatment of heavy and/or prolonged menstrual bleeding without organic cause: pooled analysis of two multinational, randomised, double-blind, placebo-controlled trials of oestradiol valerate and dienogest. Eur J Contracept Reprod Health Care. 2011;16(4): 258-269.

37. Bifulco G, Di Spiezio Sardo A, De Rosa N, et al. The use of an oral contraceptive containing estradiol valerate and dienogest before office operative hysteroscopy: a feasibility study. Gynecol Endocrinol. 2012;28(12):949-955.

38. De Leo V, Fruzzetti F, Musacchio MC, Scolaro V, Di Sabatino A, Morgante G. Effect of a new oral contraceptive with estradiol valerate/dienogest on carbohydrate metabolism. Contraception. 2013;88(3):364-368.

39. Bitzer J, Parke S, Roemer T, Serrani M. Endometrial safety of an oral contraceptive containing estradiol valerate and dienogest. Int JWomens Health. 2011;3:127-132.

40. Di Carlo C, Gargano V, Sparice S, et al. Short-term effects of an oral contraceptive containing oestradiol valerate and dienogest on bone metabolism and bone mineral density: an observational, preliminary study. Eur J Contracept Reprod Health Care. 2013;18(5):388-393.

41. Mueck AO, Seeger H, Bühling KJ. Why use of dienogest for the first contraceptive pill with estradiol? Gynecol Endocrinol. 2010;26(2):109-113.

42. Mueck AO. Dinogest: an oral progestogen for the treatment of endometriosis. Expert Rev Obstet Gynecol. 2011;6(1):5-15.

43. Lefebvre G, Pinsonneault O, Antao V, et al; SOGC. Primary dysmenorrhea consensus guideline. J Obstet Gynaecol Can. 2005;27(12): 1117-1146.

44. Hallberg L, Högdahl AM, Nilsson L, Rybo G. Menstrual blood loss a population study. Variation at different ages and attempts to define normality. Acta Obstet Gynecol Scand. 1966;45(3):320-351.

45. Munro MG, Critchley HO, Broder MS, Fraser IS; FIGO Working Group on Menstrual Disorders. FIGO classification system (PALMCOEIN) for causes of abnormal uterine bleeding in nongravid women of reproductive age. Int J Gynaecol Obstet. 2011;113(1):3-13.

46. Hallberg L, Nilsson L. Determination of menstrual blood loss. Scand $J$ Clin Lab Invest. 1964;16:244-248.

47. Kaunitz AM, Bissonnette F, Monteiro I, Lukkari-Lax E, Muysers C, Jensen JT. Levonorgestrel-releasing intrauterine system or medroxyprogesterone for heavy menstrual bleeding: a randomized controlled trial. Obstet Gynecol. 2010;116(3):625-632.
48. Andersson JK, Rybo G. Levonorgestrel-releasing intrauterine device in the treatment of menorrhagia. Br J Obstet Gynaecol. 1990;97(8): 690-694.

49. Reid PC, Virtanen-Kari S. Randomised comparative trial of the levonorgestrel intrauterine system and mefenamic acid for the treatment of idiopathic menorrhagia: a multiple analysis using total menstrual fluid loss, menstrual blood loss and pictorial blood loss assessment charts. BJOG. 2005;112(8):1121-1125.

50. Tang GW, Lo SS. Levonorgestrel intrauterine device in the treatment of menorrhagia in Chinese women: efficacy versus acceptability. Contraception. 1995;51(4):231-235.

51. Sulak PJ, Scow RD, Preece C, Riggs MW, Kuehl TJ. Hormone withdrawal symptoms in oral contraceptive users. Obstet Gynecol. 2000;95(2):261-266

52. Sulak P, Willis S, Kuehl T, Coffee A, Clark J. Headaches and oral contraceptives: impact of eliminating the standard 7-day placebo interval. Headache. 2007;47(1):27-37.

53. Bitzer J. Hormone withdrawal-associated symptoms: overlooked and under-explored. Gynecol Endocrinol. 2013;29(6):530-535.

54. World Health Organization. Medical Eligibility Criteria for Contraceptive Use. 4th ed. Geneva: World Health Organization; 2010. Available from: http://whqlibdoc.who.int/publications/2010/9789241563888_eng.pdf. Accessed January 22, 2014

55. Centers for Disease Control and Prevention. US medical eligibility criteria for contraceptive use 2010. MMWR. 2010;59:1-86.

56. Edlow AG, Bartz D. Hormonal contraceptive options for women with headache: a review of the evidence. Rev Obstet Gynecol. 2010;3(2):55-65.

57. Sitruk-Ware R. New progestagens for contraceptive use. Hum Reprod Update. 2006;12(2):169-178.

58. Milsom I, Andersson K, Andersch B, Rybo G. A comparison of flurbiprofen, tranexamic acid, and a levonorgestrel-releasing intrauterine contraceptive device in the treatment of idiopathic menorrhagia. Am J Obstet Gynecol. 1991;164(3):879-883.

59. Xiao B, Wu SC, Chong J, Zeng T, Han LH, Luukkainen T. Therapeutic effects of the levonorgestrel-releasing intrauterine system in the treatment of idiopathic menorrhagia. Fertil Steril. 2003;79(4):963-969.

60. Shaaban MM, Shabaan MM, Zakherah MS, El-Nashar SA, Sayed GH. Levonorgestrel-releasing intrauterine system compared to low dose combined oral contraceptive pills for idiopathic menorrhagia: a randomized clinical trial. Contraception. 2011;83(1):48-54.

61. Lukes AS, Moore KA, Muse KN, et al. Tranexamic acid treatment for heavy menstrual bleeding: a randomized controlled trial. Obstet Gynecol. 2010;116(4):865-875

62. Center for Drug Evaluation and Research. Application number: 22-252, Original 1. Statistical Review(s). http://www.accessdata.fda.gov/drugsatfda_docs/nda/2010/022252_Orig-1_StatR.pdf. U.S. Department of Health and Human Services, Food and Drug Administration; 2010. Accessed July 7, 2014.
International Journal of Women's Health

\section{Publish your work in this journal}

The International Journal of Women's Health is an international, peerreviewed open-access journal publishing original research, reports, editorials, reviews and commentaries on all aspects of women's healthcare including gynecology, obstetrics, and breast cancer. The manuscript management system is completely online and includes
Dovepress

a very quick and fair peer-review system, which is all easy to use. Visit http://www.dovepress.com/testimonials.php to read real quotes from published authors. 